\title{
Os direitos da criança intersexual à luz da lei de registros públicos
}

\section{The rights of the intersexual child under the public records law}

\author{
Thaís Vieira Borges ${ }^{1}$, Danilo Henrique Nunes ${ }^{1}$ \\ ${ }^{1}$ Centro Universitário da Fundação Educacional de Barretos (UNIFEB) - Barretos (SP), Brasil.
}

\begin{abstract}
Resumo
O presente estudo aborda a tutela acerca da intersexualidade humana, partindo do princípio de preservar a identidade sexual como meio garantidor do direito humano à identidade. Nesse sentido, a intersexualidade humana, em breve síntese, nada mais é que um fenômeno orgânico oriundo de um desequilíbrio entre os fatores e eventos responsáveis pela determinação e diferenciação sexual, que se evidencia quando o indivíduo possui ambiguidade de genitálias, anomalias ou incongruências no componente da sua identidade sexual. Desse modo, a parte mais delicada e que mais precisa de estudos aprofundados, quando se trata de crianças intersexuadas, é no que se refere ao seu registro civil de nascimento, visto que há necessidade de modificação na Lei de Registros Públicos (Lei n ${ }^{\circ}$ 6.015/73), no sentido de resguardar a mínima dignidade desses menores impúberes, pois, no atual cenário, não há na referida lei correspondência alguma de tal garantia. Assim, o que fazer: adiar o registro e fazer os exames médicos para verificar o sexo predominante ou registrar de imediato e deixar na subjetividade do parecer do médico e dos familiares para identificação do sexo? Portanto, enquanto não houver modificação legal para tutelar o direito à identidade das crianças intersexuadas, o melhor a se fazer é aguardar a verificação da medicina por meio de exames devidamente compatíveis e só depois registrar com a identidade sexual correta.
\end{abstract}

Palavras-chave: intersexualidade; direito da criança; direito à identidade; registro público.

\begin{abstract}
This study deals with the protection of human intersexuality, based on the principle of preserving sexual identity as means of ensuring the human right to identity. In this sense, human intersexuality, in short synthesis is nothing more than an organic phenomenon, arising from an imbalance between the factors and events responsible for sexual determination and differentiation, which is evidenced when the individual has ambiguity of genitals, anomalies or incongruities in the component of their sexual identity. Thus, the most delicate and most necessary part of in-depth studies is when it comes to intersexual children and their civil birth registration. The Public Records Law - Law no. 6.015/73 needs to be modified in order to safeguard the minimum dignity of these impugned minors; since the current law scenario offers no guarantee. Therefore, the following question arises, while there is no legal solution, what to do? Postpone registration until medical examinations to verify the predominant sex or register immediately relying on the subjectivity of the opinion of the doctor and family members to identify the sex? Therefore, as long as there is no legal change to protect the right of the identity of intersexed children, the best thing to do is to wait for medical verification through properly compatible exams and then register with the correct sexual identity.
\end{abstract}

Keywords: intersexuality; child's right; right to identity; public registry.

Autor para correspondência: Thaís Vieira Borges - Centro Universitário da Fundação Educacional de Barretos (UNIFEB) - Av. Professor Roberto Frade Monte, 389 - Aeroporto - CEP: 14283-078 - Barretos (SP), Brasil - E-mail: thaatavieira@outlook.com

Recebido em: 07 de julho de 2017

Aceito para publicação em: 09 de novembro de 2017 


\section{Introdução}

A tutela acerca da intersexualidade humana parte do princípio de preservar a identidade sexual como meio garantidor do direito humano à identidade. É evidente, no entanto, a dificuldade para tal efetivação. Nesse sentido, foram trazidos os conceitos mais aceitos e atualizados sobre o tema, com a devida discussão acerca das melhores e menos traumáticas medidas para garantir o mínimo de dignidade aos intersexuais, em especial as crianças.

Nesse sentido, de enorme importância foi a aprovação da Declaração dos Direitos das Crianças (DDC) em 1959, sob a influência dos princípios que regem a Declaração Universal de Direitos Humanos,

[...] constituindo esse documento um verdadeiro divisor de águas, pois a criança passou a ser vista como sujeito de direitos, abandonando-se o conceito de que era objeto de proteção (ROSSATO; LÉPORE; CUNHA, 2014, p. 50).

O termo "sexualidade" possui conceitos históricos diferentes ao longo do tempo. Diante disso, entende-se que a intersexualidade do homem é um fenômeno orgânico oriundo de um desequilíbrio entre os fatores e eventos responsáveis pela determinação e diferenciação sexual, que se evidencia quando o indivíduo possui ambiguidade de genitálias, anomalias ou incongruências no componente da sua identidade sexual. Assim,

[...] todos os seres humanos, desde o nascimento - ou antes, já no ventre gestacional -, sempre são cobertos por um véu de sexualidades nas quais estão ligados até o momento do morrer corporal (BONFIM, 2015, p. 29).

Dessa forma, observa-se que, a partir do nascimento da criança, esta adquire personalidade, assim como direitos à vida, à saúde e, principalmente, à dignidade, propiciando toda a tutela necessária para um crescimento/desenvolvimento condigno e minimamente feliz, tudo devidamente amparado pela lei, em sentido amplo.

O principal objetivo do trabalho em tela é a abordagem dos direitos das crianças, as quais, por motivos biológicos, nascem com anomalias em seus respectivos órgãos sexuais, buscando mostrar à sociedade, por muitas vezes preconceituosa, de que é extremamente necessária uma especial atenção para os direitos daquelas que são denominadas intersexuais.
Dessa feita, denota-se a urgência social, médica e jurídica, em razão da possibilidade de danos irreparáveis, morais e/ou materiais experimentados por essas crianças intersexuais, desde o seu nascimento até a formação de seu intelecto completo.

Vale, portanto, ressaltar que os direitos das crianças intersexuais não podem ser deixados de lado, uma vez que o direito à saúde e, principalmente, à identidade é constitucionalmente previsto e, assim, deve ser respeitado por todos e pelo Estado.

Este estudo sobre os direitos das crianças intersexuais, à luz da Lei de Registros Públicos, justifica-se em razão da omissão legislativa quanto à matéria. Assim, o que deve ser feito: adiar o registro e fazer os exames médicos para verificar o sexo predominante ou registrar de imediato e deixar na subjetividade do parecer do médico e dos familiares para identificação do sexo?

\section{Material e Métodos}

A pesquisa bibliográfica foi realizada nas áreas do Direito, em especial dos Direitos Fundamentais e do Direito Notarial, e da Saúde, permeando os vários ramos da Ciência Jurídica. Fez-se necessário observar o movimento histórico, social, religioso e, principalmente, jurídico dos direitos das crianças intersexuais.

Do mesmo modo, fez-se levantamento a respeito das legislações aplicadas a serviços notariais, com especial atenção à Lei de Registros Públicos (Lei ${ }^{\circ} 6.015 / 73$ ) que elucida todo o sistema registral aplicado no território brasileiro. O método utilizado na elaboração e no desenvolvimento do presente trabalho será o método de pesquisa dedutivo, por meio de modelos teóricos do conteúdo proposto, bem como de estudo comparativo.

Da mesma forma, o estudo analítico também se deu pelo aprofundamento acerca dos direitos humanos, com foco no entendimento sobre a matéria das Cortes Superiores, trazendo um posicionamento moderno quanto à tutela dos direitos dessas crianças.

$\mathrm{O}$ trabalho científico abrangeu um conjunto sistematizado de ideias ou de verdades logicamente encadeadas entre si, sendo elas um produto cumulativo, mas não acabado de conhecimento. Todo trabalho científico comporta conhecimento em processo, comporta um conjunto geralmente de verdades provisórias, possibilitando revisões constantes e novas descobertas (KERLINGER, 1975). 
Tendo por critério a coerência, a consistência e a não contradição, demonstraram-se a lacuna legal e a omissão legislativa quanto à regularização do assentamento civil das crianças que nascerem com as anomalias e são consideradas intersexuais.

\section{Resultados e Discussão}

Acerca de seu contexto histórico, a tutela dos direitos humanos começou a ser fortemente debatida com a Declaração Universal dos Direitos do Homem, elaborada por representantes de diferentes origens jurídicas e culturais de todas as regiões do mundo. A Declaração foi proclamada pela Assembleia Geral das Nações Unidas em Paris, no dia 10 de dezembro de 1948, por meio da Resolução 217 A (III) da Assembleia Geral, como uma norma comum a ser alcançada por todos os povos e nações. Ela estabelecia, pela primeira vez, a proteção universal dos Direitos Humanos, trazendo diversas disposições que entrariam como medidas constitucionais em seus países signatários, proporcionando às pessoas o mínimo de garantia exercida pelo Estado.

Buscando a tutela dos Direitos Humanos em sua excelência, em 1959 a Assembleia Geral da Organização das Nações Unidas (ONU) editou/aprovou a Declaração dos Direitos das Crianças (DDC), norteada pelos princípios regimentais da Declaração Universal de Direitos Humanos,

[...] constituindo esse documento um verdadeiro divisor de águas, pois a criança passou a ser vista como sujeito de direitos, abandonando-se o conceito de que era objeto de proteção (ROSSATO; LÉPORE; CUNHA, 2014, p. 50).

Nesse sentido, vale ressaltar que a Assembleia Geral aprovou a Convenção sobre os Direitos da Criança em 1989, e tal documento possui "força jurídica obrigatória, cujo cumprimento poderia ser exigido dos Estados-Partes" (ROSSATO; LÉPORE; CUNHA, 2014, p. 60).

Com o passar dos anos, outros documentos que tutelam os Direitos Humanos foram sendo inseridos nos ordenamentos jurídicos dos Estados signatários. Entretanto, por mais que existam disposições no ordenamento jurídico brasileiro, em especial na Constituição Federal de 1988, nem sempre são suficientes para materializar/tutelar determinadas situações específicas no que se refere ao conflito entre o direito à identidade biológica, sexual e de gênero.
Após essa breve síntese sobre o histórico dos Direitos Humanos e também dos direitos da criança, é necessário, portanto, trazer a abordagem sobre as crianças intersexuais, pois, diante da

[...] parca evolução legislativa brasileira, principalmente no que tange o entendimento de identidade de gênero, emerge a necessidade de flexibilização dos entendimentos à luz dos princípios constitucionalmente tutelados, tendo como objetivo a tutela da pessoa humana (SOUZA, 2015, p. 56).

Nesse contexto, o termo "intersexualidade" "constitui-se como resultado de um desequilíbrio entre os fatores que determinam o sexo" (SOUZA, 2015, p. 56).

Os indivíduos apresentam caracteres tanto masculinos quanto femininos. Esse desequilíbrio ocorre de 1/4.500 nascimentos, sendo fundamental o cuidadoso exame dos genitais de todo recém-nascido para sua detecção precoce (DAMIANI; GUERRA-JÚNIOR, 2007; VILAR, 2009).

Nesse aspecto, modernamente, em termos biomédicos, o intersexo possui classificação por meio de quatro grandes grupos, quais sejam: hermafrodismo verdadeiro, disgenesia gonadal mista, pseudo-hermafrodismo masculino e pseudo-hermafrodismo feminino.

A palavra "hermafrodita" tem origem do mito grego "hermafrodito" (CANGUÇU-CAMPINHO; LIMA, 2014). Por muito tempo, pensou-se no hermafrodita como um ser monstruoso, por abalar a ordem "natural". O século XX quebrou barreiras quanto ao entendimento acerca da intersexualidade, pois esta

[...] sai do campo moral para inserir-se nas más-formações; os intersexuais passam a ser percebidos pela sociedade como seres incompletos que devem recorrer, o mais cedo possível, aos cuidados médicos (SOUZA, 2015, p. 64)

Nesse sentido, Costa (2012, p. 15) anota que "a intersexualidade deslizou do registro da monstruosidade para o do indivíduo passível de correção".

A utilização da terminologia "intersexo" já não se faz mais adequada, uma vez que traz a ideia de um terceiro sexo. Assim, passou a ser utilizada a terminologia Anomalia do Desenvolvimento Sexual (ADS) ou Desordem do Desenvolvimento Sexual (DDS) (DAMIANI; GUERRA-JUNIOR, 2007).

$\mathrm{O}$ "estigma em relação às pessoas com intersexo" é um assunto delicado. (SOUZA, 2015, p.65). A participação médica, nesses casos, é fundamental, 
e, por vezes, o tratamento pode se alongar além do previsto, pois, em algumas circunstâncias, há “[...] a necessidade de realização de exames, da utilização de medicamentos e, em alguns casos, da realização de cirurgias corretivas" (CANGUÇU-CAMPINHO e LIMA, 2014, p. 184).

O sujeito que possui ADS ou DDS ainda enfrenta o preconceito da sociedade perante a sua situação, pois, por causa de pouca matéria científica e divulgação da imprensa, paira sobre a maioria das pessoas a ignorância (GUERRA-JUNIOR; MACIEL-GUERRA, 2007).

As pessoas em situação de intersexo com ambiguidade externa, em alguns casos, apresentam extremo sofrimento, o que acaba ocasionando o suicídio desses indivíduos. Por isso, existe a preocupação com as crianças que ainda estão nessa situação excepcional e com seu desenvolvimento psicológico em formação.

Desse modo, as mudanças biológicas acontecem sem a vontade do indivíduo, pois uma criança que nasceu com ambiguidade de genitálias não tinha o pensamento nem o sentimento em ser dessa forma. De acordo com a Lei de Registros Públicos, os pais da criança devem registrá-la logo após o nascimento, indicando, assim, o nome dela e automaticamente o sexo visível.

Em contrapartida, é possível compreender o sentimento dos pais ao não saberem identificar o sexo de seu amado filho que acabou de nascer. Não é normal o nascimento de crianças intersexuais, contudo não há previsão específica na Lei de Registros Públicos quanto ao assentamento civil sobre essa situação excepcional.

Um método interessante que está sendo bem-visto e utilizado na Alemanha é o de não especificar o sexo da criança em sua certidão até que fique provado, por meio de um extenso processo de exames precisos, o sexo predominante.

A humanidade está evoluindo cada vez mais, e, dessa forma, os indivíduos necessitam de uma facilidade para que a dignidade humana seja cada vez mais respeitada. Após saber de todos os perigos que um intersexo pode passar, deve-se pensar sobre a responsabilidade dada aos responsáveis de registrar essa criança assim que ela nasce sem ter a certeza do sexo predominante. Talvez esse não seja o melhor caminho, uma vez que estão inseridos diversos fatores para a definição do sexo predominante. Entregar aos pais tamanha responsabilidade é, por vezes, muito cruel, pois, independentemente da decisão, os genitores, de forma automática, estarão, ainda que sem a mínima intenção, ferindo cruelmente os direitos à identidade e à personalidade dessa pobre criança.

Diante do complexo jurídico, sociológico e biológico acerca desse fenômeno, o Conselho Federal de Medicina (CFM) editou a Resolução $\mathrm{n}^{\mathrm{o}} 1.664 / 2003$, estabelecendo a conduta minimamente adequada ao tratamento desses pacientes intersexuais.

[...] De acordo com este documento, faz-se necessária uma conduta de investigação precoce em virtude de a intersexualidade poder vir a se configurar em uma urgência biológica e social (FRASER, 2012, p. 1).

A urgência social se personifica em razão dos

[...] impactos psicológicos e sociais que o nascimento da criança intersexuada ocasiona para a família e para o próprio paciente, além dos graves transtornos à vida e ao bem-estar do indivíduo em casos de erro da definição sexual, seja por ocasionar caracteres sexuais secundários opostos ao sexo previamente definido, bem como pela possibilidade da degeneração maligna das gônadas (FRASER, 2012, p. 1).

O próprio CFM, de acordo com o disposto no artigo $4^{\circ}$ da Resolução $n^{\circ} 1.664 / 2003$, estabeleceu a obrigatoriedade de uma equipe multidisciplinar para definição final, após diversos exames, do sexo predominante, com o intuito de diminuir os riscos do desenvolvimento dessa criança.

Daí faz-se necessária uma modificação na Lei de Registros Públicos, tendo em vista que, atualmente, conforme dito antes, não há exceção para o assentamento dessas crianças portadoras de intersexo. Assim, entende-se que a modificação deve abrir a possibilidade de registrar-se tardiamente, depois de estudos feitos por equipe multidisciplinar ou, em casos de impossibilidade de anotação de sexo predominante, autorizar, conforme se faz na Alemanha, o assentamento sem a gravação no local da determinação do sexo.

Foram analisadas como positivas as experiências trazidas da Alemanha, bem como a possibilidade constitucional de implantação de tais medidas. Desse modo, ainda que precariamente, os médicos brasileiros, conforme resolução de seu órgão colegiado, retardam a definição do sexo para que, após exames, informem o sexo predominante da criança. Ao que parece, diante da omissão legislativa, essa é a única opção para dar aos portadores dessas anomalias o mínimo de dignidade humana, sendo tutelados seus direitos à identidade e prestigiando sua personalidade (figura 1). 


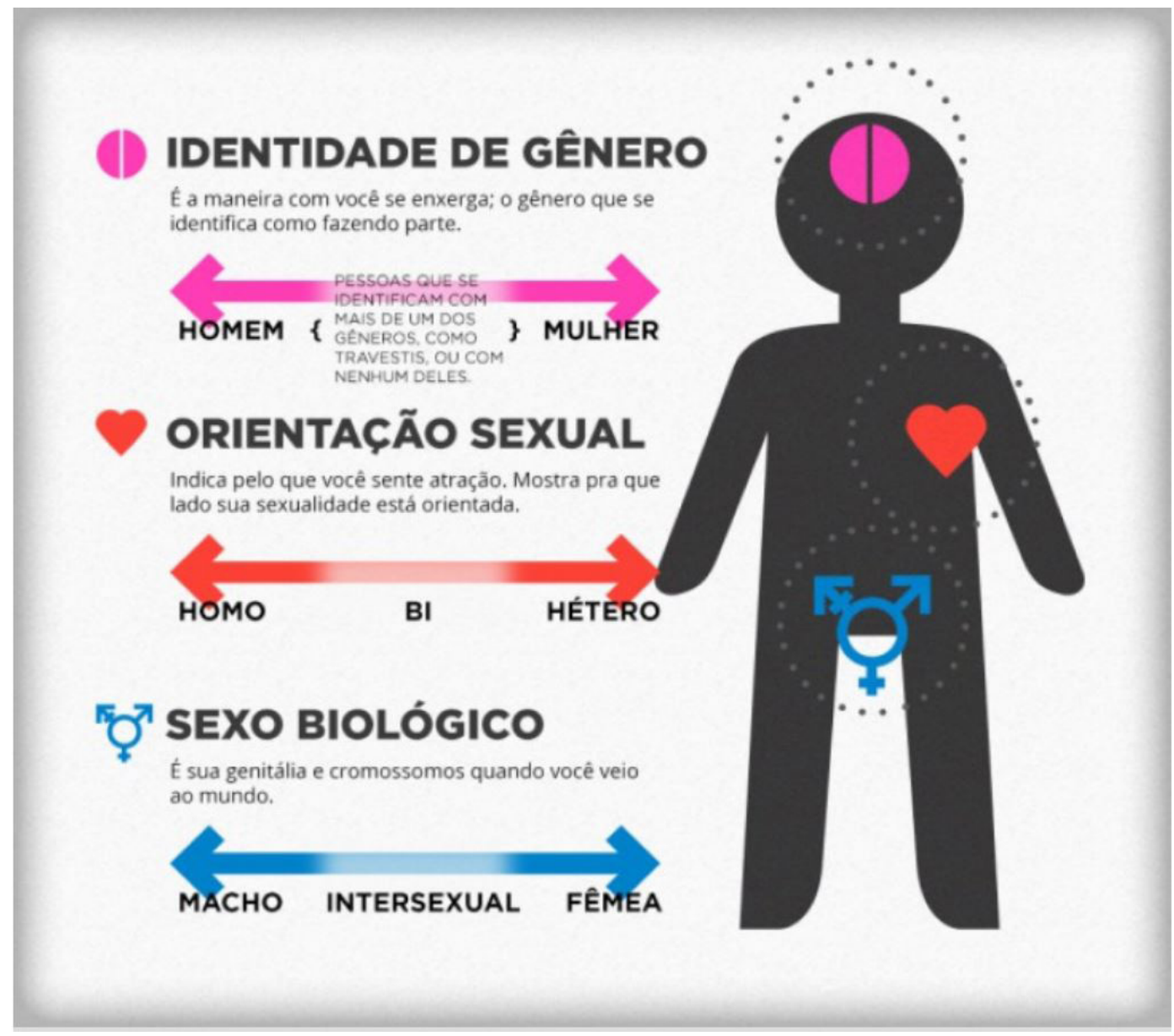

Figura 1. FRASER, R. T. D. Intersexualidade e direito à identidade: uma discussão sobre o assentamento civil de crianças intersexuadas. Disponível em: <http://www.ceert.org.br/noticias/ genero-mulher/11459/intersexualidade-e-direito-a-identidade-uma-discussao-sobre-o-assentamentocivil-de-criancas-intersexuadas>. Acesso em: 20 nov. 2016.

\section{Conclusão}

O Direito, enquanto instrumento de controle social e, principalmente, meio de materialização de tutela das necessidades do indivíduo, traz como principais características a sua dinamicidade e dialeticidade. Com isso, é de bom alvitre a utilização de referidos instrumentos para encontrar uma solução que proteja os direitos à saúde, à dignidade e à identidade daquelas pequeninas crianças que, devido a anomalias genéticas, nascem intersexuadas.

A intersexualidade humana, infelizmente, é uma questão de saúde pública e, por essa característica, não pode ser simplesmente ignorada pelas autoridades do Estado.
No Brasil, o tema "intersexualidade humana" é pouco debatido por se tratar, para muitos, de um assunto "assustador" e que gera muita polêmica, pois, além de envolver a parte dos direitos dessas pessoas, ainda esbarra nas doutrinas religiosas.

A Lei de Registros Públicos (Lei no 6.015/73), no que se refere ao assentamento de nascimento civil, ainda é bem restrita, uma vez que, quando editada, trouxe critérios objetivos para seu preenchimento, ou seja, no campo do sexo do recém-nascido, opta-se pelas formas "masculino" ou "feminino", mas não traz nenhuma exceção quanto às pessoas que possuem ADS ou DDS, conhecidas como intersexuais.

O assunto em análise extrapola as barreiras do Direito, mas esbarra na Medicina, pois é dependente 
desta, na maioria das vezes, para solucionar seus conflitos. Daí surge a discussão do que fazer para garantir às crianças intersexuadas o seu direito constitucional à identidade e, ao mesmo tempo, solucionar problemas registrais e dar uma resposta aos familiares.

A necessidade de adequar-se a essa singularidade é emergente. Assim, uma hipótese de solução para o conflito seria uma mudança legislativa, na qual continuaria a previsão do sexo biológico como masculino ou feminino, mas traria a excepcionalidade de o tabelião facultar-se de não inserir expressão de sexo quando tratar-se de registro de crianças que nasceram com a anomalia em seu desenvolvimento sexual. Além disso, seria estabelecido um prazo minimamente razoável para que, após devidamente realizados exames multidisciplinares por médicos especialistas, seja possível identificar o sexo predominante e, por consequência, retificar $\mathrm{o}$ assentamento civil.

Finalmente, pondera-se que nem sempre as mudanças legislativas acontecem no Brasil. Portanto, como medida emergencial e provisória, deve-se seguir o que já foi preconizado no artigo $4^{\circ}$ da Resolução $n^{\circ} 1.664 / 2003$ do CFM, que estabelece a obrigatoriedade de uma equipe multidisciplinar de médicos especializados e de outros profissionais da área da saúde e assistência social para definição final, depois de diversos exames determinarem o sexo predominante, com o intuito de diminuir os riscos do desenvolvimento dessa criança.

Portanto, espera-se que, no futuro próximo, seja possível olhar para trás e visualizar que os direitos à dignidade e, principalmente, à identidade das crianças intersexuais tenham sido respeitados e que elas possuam uma vida digna em uma sociedade em que todos tratem-nas como semelhantes.

\section{Referências}

BOMFIM, U. F. P. O direito como instrumento protetor dos vulnerados na seara das sexualidades. Tese (Doutorado) - Faculdade de Direito da Universidade Federal da Bahia, Salvador: Bomfim, 2015.

BRASIL. Senado Federal. Resolução 217. Assembleia Geral das Nações Unidas em Paris, de 10 de dezembro de 1948. Disponível em: <https://www2.senado. leg.br/bdsf/bitstream/handle/id/508144/000992124. pdf?sequence $=1>$. Acesso em: 10 set. 2016.

. Lei n ${ }^{\circ} 6.015$, de 31 de dezembro de 1973.

Dispõe sobre os registros públicos e dá providências.
Disponível em: <http://www.planalto.gov.br/ ccivil_03/leis/16015.htm>. Acesso em: 10 set. 2016.

. Conselho Federal de Medicina. Resolução $\mathrm{n}^{\circ} 1.664 / 2003$, de 13 de maio de 2003. Define as normas técnicas necessárias para o tratamento de pacientes portadores de anomalias de diferenciação sexual. Diário Oficial [da] República Federativa do Brasil, Brasília, DF, 13 maio. 2003. Seção 1, p. 101.

CANGUÇU-CAMPINHO, A. K.; LIMA, I. M. S. O. Dignidade da Criança em situação de intersexo: orientação para família. Salvador: UFBA/ UCSAL, 2014.

COSTA, L. S. A invisibilidade da intersexualidade na saúde pública: reflexões a partir da inserção do psicólogo na saúde. Monografia - UniCEUB, Centro Universitário de Brasília. 2012.

DAMIANI, D.; GUERRA-JÚNIOR, G, VILAR. As novas definições e classificações dos estados intersexuais: o que o Consenso de Chicago contribui para o estado da arte? Arq Bras Endocrinol Metab, São Paulo, v. 51, n. 6, Aug. 2007.

FRASER, R. T. D.; LIMA, I. M. S. O. Intersexualidade e direito à identidade: uma discussão sobre o assentamento civil de crianças intersexuadas. 2012. Disponível em: $<$ https://robertafraser.jusbrasil.com. br/artigos/112106431/intersexualidade-e-direito-aidentidade-uma-discussao-sobre-o-assentamentocivil-de-criancas-intersexuadas $>$. Acesso em: 20 set. 2016.

GUERRA-JÚNIOR, G; MACIEL-GUERRA,A.T. $O$ pediatra frente a uma criança com ambiguidade genital. J Pediatr (Rio J), Porto Alegre, v. 83, n. 5, nov. 2007.

KERLINGER, F. Metodologia da pesquisa em ciências sociais. São Paulo: EPU, 1975.

ROSSATO, L. A.; LÉPORE, P. E.; CUNHA, R.S. Estatuto da criança e do adolescente comentado artigo por artigo. 6. ed. rev. atual. e ampl. São Paulo: Revista dos Tribunais, 2014.

SOUZA, A. S. Os direitos da personalidade e autonomia privada: a questão das crianças em situação de intersexo. Dissertação - Universidade Federal da Bahia, Salvador, 2015. 